\title{
Application of Electron Paramagnetic Resonance Spectroscopy for Validation of the Novel (AN+DN) Solvent Polarity Scale
}

\author{
Luciana Malavolta ${ }^{1,3}$, Erick F. Poletti ${ }^{1}$, Elias H. Silva ${ }^{1}$, Shirley Schreier ${ }^{2}$ and Clovis R. Nakaie ${ }^{1, *}$
}

1 Department of Biophysics, Universidade Federal de Sao Paulo (Unifesp), Rua 3 de Maio 100, CEP 04044-020, São Paulo, SP, Brazil. E-Mails: luciana@biofis.epm.br (L. M.); erick@biofis.epm.br (E. P.); ehsilva@biofis.epm.br (E. S.)

2 Department of Biochemistry, Institute of Chemistry, Universidade de Sao Paulo, Sao Paulo, Brazil. E-Mail: schreier@iq.usp.br(S.S.)

3 Instituto Israelita de Ensino e Pesquisa Albert Einstein, Sao Paulo, SP, Brazil

* Author to whom correspondence should be addressed; E-Mail: clovis@biofis.epm.br; Tel.: +55-115039-0809; Fax: +55-11-5575-9617

Received: 24 April 2008; in revised form: 3 July 2008 / Accepted: 4 July 2008 / Published: 17 July 2008

\begin{abstract}
Based on solvation studies of polymers, the sum (1:1) of the electron acceptor (AN) and electron donor (DN) values of solvents has been proposed as an alternative polarity scale. To test this, the electron paramagnetic resonance isotropic hyperfine splitting constant, a parameter known to be dependent on the polarity/proticity of the medium, was correlated with the $(\mathrm{AN}+\mathrm{DN})$ term using three paramagnetic probes. The linear regression coefficient calculated for 15 different solvents was approximately 0.9 , quite similar to those of other well-known polarity parameters, attesting to the validity of the $(\mathrm{AN}+\mathrm{DN})$ term as a novel "two-parameter" solvent polarity scale.
\end{abstract}

Keywords: polarity; solvent; EPR; spin label; isotropic hyperfine splitting constant

\section{Introduction}

No single solvent polarity scale has yet been accepted as being the most appropriate for interpreting solvent effects. The findings obtained to date only underscore the difficulties in attaining a consensus regarding the rules that might govern solute-solvent interactions. A great number of empirical polarity scales based on experimental studies have been proposed, most of which employed single solute- 
models in order to investigate (spectroscopically, thermodynamically, kinetically, etc.) the interaction between solutes and solvents of different polarities [1,2].

In a conceptual departure from most prior efforts to define an accurate polarity term, we previously proposed an alternative polarity scale based on experiments designed to assess solvation of model resins and peptide-resin (microscopic measurement of bead swelling) in solvent systems broadly encompassing the polarity scale [3, 4]. In these works, we have hypothesized that the 1:1 sum of Gutman's [5] electron acceptor number (AN) and electron donor number (DN) numbers would be a dimensionless, accurate polarity term. Due to the presence of opposing concepts within the same parameter, the $(\mathrm{AN}+\mathrm{DN})$ term was denoted an amphoteric constant or scale [6]. The application of this novel polarity constant can facilitate the prediction of polymer or peptide-polymer solvation, thereby improving techniques such as solid-phase peptide synthesis [7-9]. In addition, the acquisition of specific knowledge regarding this type of solute-solvent interaction process has been of great value for the development of advantageous experimental approaches in the field [10-12]. Furthermore, the combination of the antagonic AN and DN concepts has also been extremely useful for understanding certain rules that govern solubilization of intractable and strong aggregate solutes [13, 14], including peptides responsible for the development of neurodegenerative disorders such as Alzheimer's disease $[15,16]$.

In the interest of continuously evaluating the validity of the newly-introduced (AN+DN) scale, the present study of solvent polarity evaluates the well-known dependence of the electron paramagnetic resonance (EPR) isotropic hyperfine splitting constant $\left(\mathrm{a}_{\mathrm{N}}\right)$ on the polarity of the medium. This spectral parameter is strongly affected by the proticity and therefore by the polarity of the medium as a consequence of the proton acceptor nitroxyl group containing the unpaired electron of the paramagnetic molecules [17-20]. Greater polarity or proticity of the medium results in higher $a_{N}$ values, since the unpaired electron is induced to localize more closely to certain atoms, such as the nitrogen atom of the $\mathrm{N}-\mathrm{O}$ moiety of the probe.

From among the different types of paramagnetic probes, the following nitroxide-radical spin labels were selected for the present study: (A) 2,2,6,6-tetramethyl-4-piperidone-1-oxide; (B) 5,4-hydantoin2,2,6,6-tetramethyl-4-piperidone-1-oxide and (C) 3-carbamoyl-2,2,5,5-tetramethyl-3-pyrrolin-1-yloxy (Figure 1). Spin labels (A) and (B) are precursors of the amino acid-type spin probes 2,2,6,6tetramethylpiperidine-1-oxyl-4-amino-4-carboxylic acid (TOAC) and 2,2,5,5-tetramethylpyrrolidine1-oxyl-3-amino-4-carboxylic acid (POAC) [21, 22], both further chemically derived for allowing their pioneering insertion within a peptide sequence [23-25]. The EPR spectra of these three spin probes were recorded for 15 single solvents, and binary correlations were drawn between the $a_{N}$ values and the $(\mathrm{AN}+\mathrm{DN})$ terms. For comparison, binary correlations were also drawn between the $\mathrm{a}_{\mathrm{N}}$ values and other known polarity scales. Among these, the Dimroth-Reichardt $\mathrm{E}_{\mathrm{T}}(30)$ parameter [26], the Hildebrand solubility term $(\delta)$ [27] and the dielectric constant $\varepsilon$ [28] were selected. Gutman's AN and DN numbers [5] were also examined in isolation within this polarity- $\mathrm{a}_{\mathrm{N}}$ relationship.

\section{Results and Discussion}

The three spin probes used as models for the present study (Figure 1) were dissolved at a final concentration of $5 \times 10^{-5} \mathrm{M}$ in order to avoid saturation effects in the solvents listed in Table 1 below. 
This Table also presents the AN, DN, $(\mathrm{AN}+\mathrm{DN}), \mathrm{E}_{\mathrm{T}}(30), \delta$ and $\varepsilon$ values found in the literature for the 15 solvents listed. The first two solvent parameters were added because some authors have considered them to be polarity parameters [29].

Figure 1. Structures of (A) 2,2,6,6-tetramethyl-4-piperidone-1-oxide; (B) 5-4-hydantoin2,2,6,6-tetramethyl-4-piperidone-1-oxide; and (C) 3-carbamoyl-2,2,5,5-tetramethyl-3pyrrolin-1-yloxy.

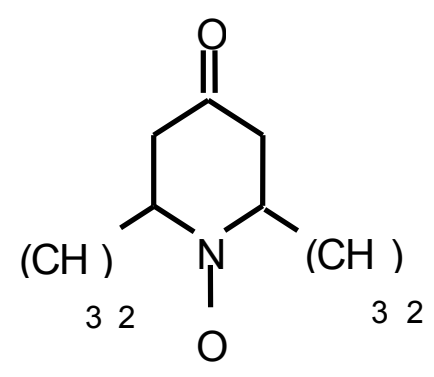

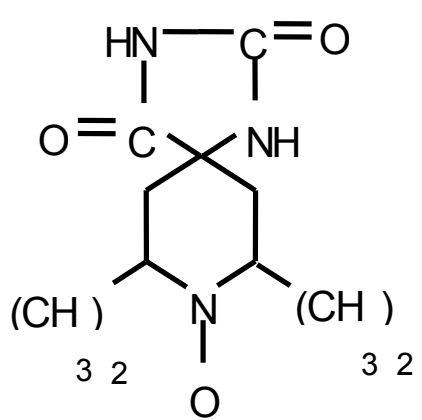

(C)

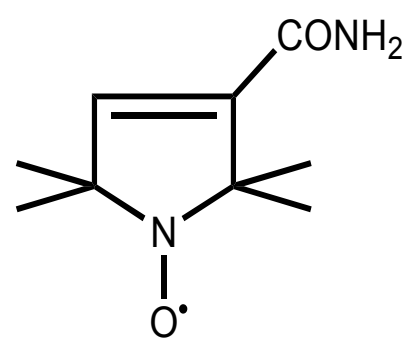

The EPR spectra of the spin label in these solvents were acquired at $9.5 \mathrm{GHz}$, and $\mathrm{a}_{\mathrm{N}}$ values were determined by measuring the distance (in Gauss) between the $h_{+1}$ and $h_{0}$ EPR peaks. Figure 2 displays the EPR spectra of the three paramagnetic probes in dimethyl sulfoxide. As expected, narrow lines were observed, reflecting the high level of activity of these small molecules in isotropic medium [30].

Figures 3 to 5 show the correlations found between the $a_{N}$ values of probes in the solvents listed in Table 1 and their $\mathrm{AN}, \mathrm{DN},(\mathrm{AN}+\mathrm{DN}), \mathrm{E}_{\mathrm{T}}(30), \delta$ and $\varepsilon$ values. It can be seen that the linear correlations were of different degrees, depending on the solvent term and on the type of paramagnetic probe.

To determine which solvent property presented a stronger linear correlation with the $\mathrm{a}_{\mathrm{N}}$ parameter, a comparative study was conducted (Table 2). The average linear regression coefficients (r) were calculated for all conditions. Among the solvent parameters, the $\mathrm{AN}, \mathrm{E}_{\mathrm{T}}(30)$ and $(\mathrm{AN}+\mathrm{DN})$ presented the strongest linear correlations, followed by $\delta, \mathrm{DN}$ and the dielectric constant $\varepsilon$.

It is noteworthy that, in agreement with the results of earlier investigations with polymers, the dielectric constant presented the weakest correlation with the polarity of the medium. This finding with this solvent parameter is indeed expected as according to several reports in the literature, it is dependent on the class of solvent [31-33]. The dielectric constant varies when the solvent form or not hydrogen bonds and/or van der Waals interactions with the $\mathrm{N}-\mathrm{O}$ moiety of the spin probes, inducing redistribution of the electrons in the medium. This is the case of alcohols such as methanol and propanol in the first class of solvent and ethyl acetate and acetone in the second. In the latter case, a weaker attraction between the Lewis base $\mathrm{N}-\mathrm{O}$ groups of the spin probe and permanent or induced dipoles of the apolar solvent molecules may occur [19]. Nevertheless, due to the small amount of solvent systems assayed in this study, it was not possible to distinguish (in Figures 3 to 5), characteristic curves for each class of solvents (polar or apolar). 
Table 1. Solvent Parameters.

\begin{tabular}{|c|c|c|c|c|c|c|c|}
\hline & Solvent & $\mathbf{A} \mathbf{N}^{\mathbf{a}}$ & $\mathbf{D N}^{\mathbf{a}}$ & $(A N+D N)^{b}$ & $\begin{array}{c}\mathbf{E}_{\mathrm{T}}(30)^{\mathrm{c}} \\
(\mathrm{kcal} / \mathrm{mol})\end{array}$ & $\begin{array}{c}\delta^{\mathrm{d}} \\
(\mathrm{cal} / \mathrm{mL})^{1 / 2}\end{array}$ & $\varepsilon^{e}$ \\
\hline 1 & Toluene & 3.3 & 0.1 & 3.4 & 33.0 & 8.9 & 2.4 \\
\hline 2 & Carbon tetrachloride & 8.6 & 0.0 & 8.6 & 32.4 & 8.6 & 2.2 \\
\hline 3 & 1,2-Dichloroethane & 16.7 & 0.0 & 16.7 & 41.3 & 9.9 & 10.1 \\
\hline 4 & DCM & 20.4 & 1.0 & 21.4 & 40.7 & 9.7 & 8.9 \\
\hline 5 & Ethyl acetate & 9.3 & 17.1 & 26.4 & 38.1 & 9.0 & 6.0 \\
\hline 6 & THF & 8.0 & 20.0 & 28.0 & 37.4 & 9.1 & 7.5 \\
\hline 7 & Acetone & 12.5 & 17.0 & 29.5 & 42.2 & 9.6 & 20.7 \\
\hline 8 & Acetonitrile & 18.9 & 14.1 & 33.0 & 45.6 & 11.9 & 36.0 \\
\hline 9 & NMP & 13.3 & 27.3 & 40.6 & 42.2 & 11.3 & 33.0 \\
\hline 10 & Dimethylacetamide & 13.6 & 27.8 & 41.4 & 42.9 & 10.8 & 37.8 \\
\hline 11 & DMF & 16.0 & 26.6 & 42.6 & 43.8 & 12.1 & 36.7 \\
\hline 12 & DMSO & 19.3 & 29.8 & 49.1 & 45.1 & 12.0 & 46.7 \\
\hline 13 & $\mathrm{EtOH}$ & 37.1 & 32.0 & 69.1 & 51.9 & 12.7 & 24.3 \\
\hline 14 & Propanol & 33.5 & 36.0 & 69.5 & 48.4 & 11.4 & 18.3 \\
\hline 15 & $\mathrm{MeOH}$ & 41.3 & 30.0 & 71.3 & 55.4 & 14.5 & 32.6 \\
\hline
\end{tabular}

dimethylformamide; DMSO: dimethyl sulfoxide; EtOH: ethanol; MeOH: methanol

${ }^{\mathrm{a}}$ Ref . 29; ${ }^{\mathrm{b}}$ Refs. 3-4; ${ }^{\mathrm{c}}$ Ref. 26; ${ }^{\mathrm{d}}$ Ref. $27 ;{ }^{\mathrm{e}}$ Ref. 28

Figure 2. Electron paramagnetic resonance spectra of (a) 2,2,6,6-tetramethyl-4piperidone-1-oxide; (b) 5,4-hydantoin (2,2,6,6-tetramethyl-4-piperidone-1-oxide; and (c) 3-carbamoyl-2,2,5,5-tetramethyl-3-pyrrolin-1-yloxy. Concentration of samples: $5 \times 10^{-5}$ $\mathrm{M}$ of each component in dimethyl sulfoxide.

(a)

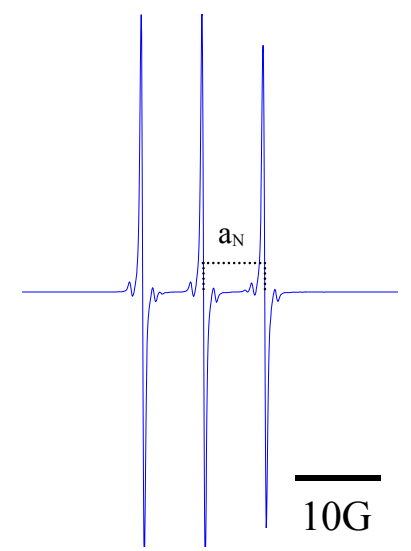

(b)

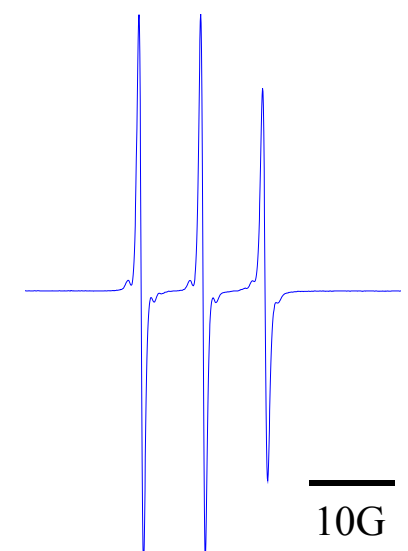

(c)

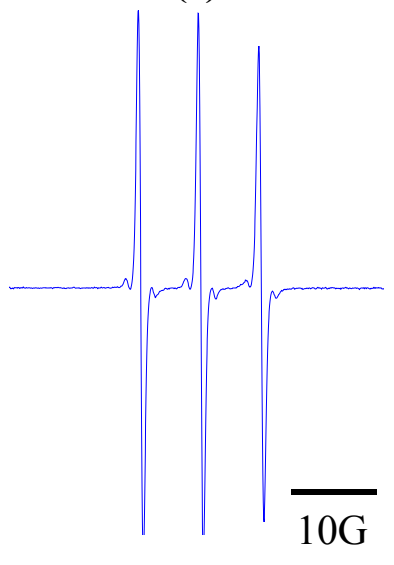


Figure 3. Values of $\mathrm{a}_{\mathrm{N}}$ of nitroxide (A) as a function of solvent $A N, D N,(A N+D N)$, $\mathrm{E}_{\mathrm{T}} 30, \delta$ and $\varepsilon$.
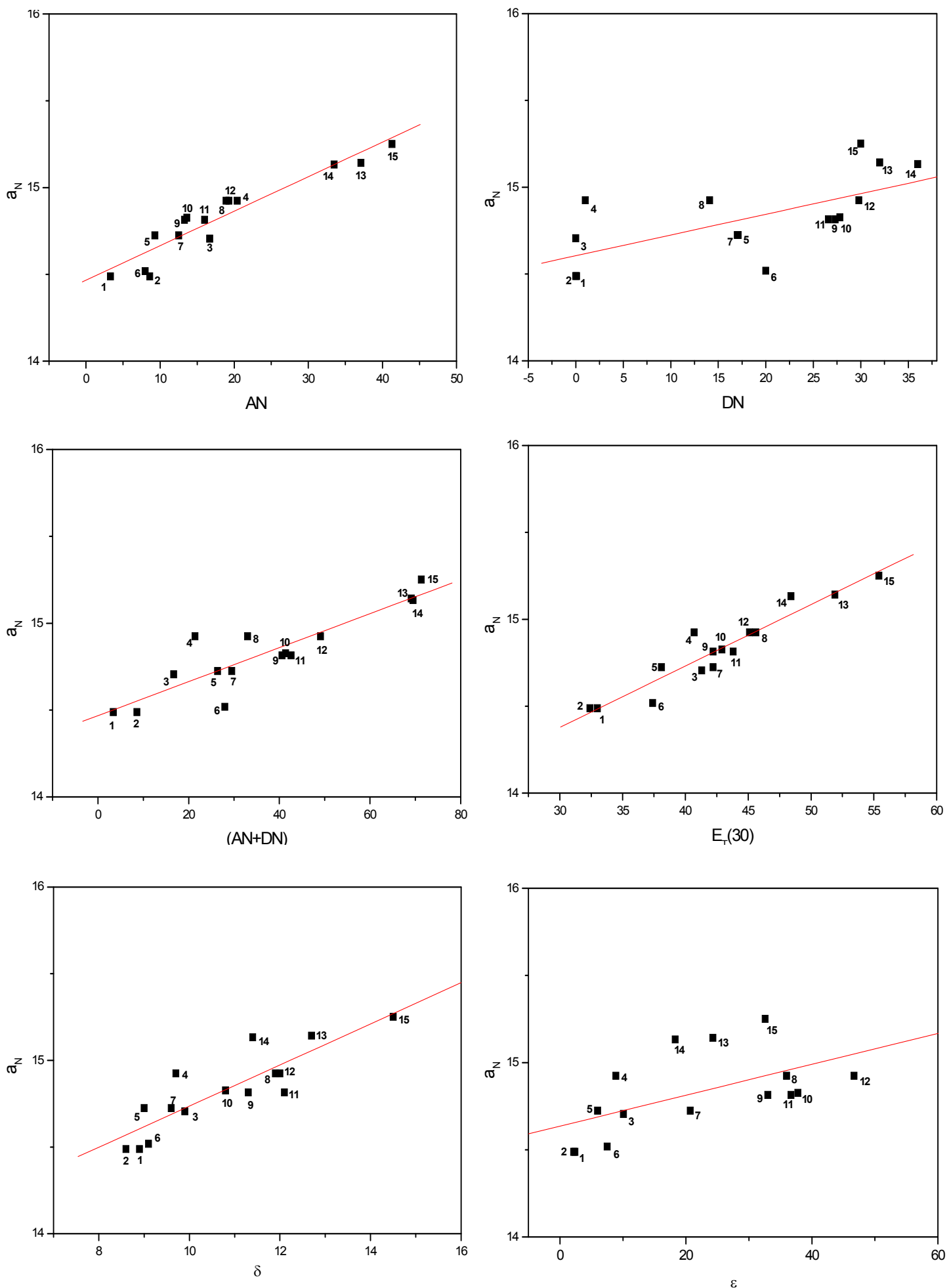
Figure 4. Values of $\mathrm{a}_{\mathrm{N}}$ of nitroxide (B) as a function of solvent $A N, D N,(A N+D N)$, $\mathrm{E}_{\mathrm{T}} 30, \delta$ and $\varepsilon$.
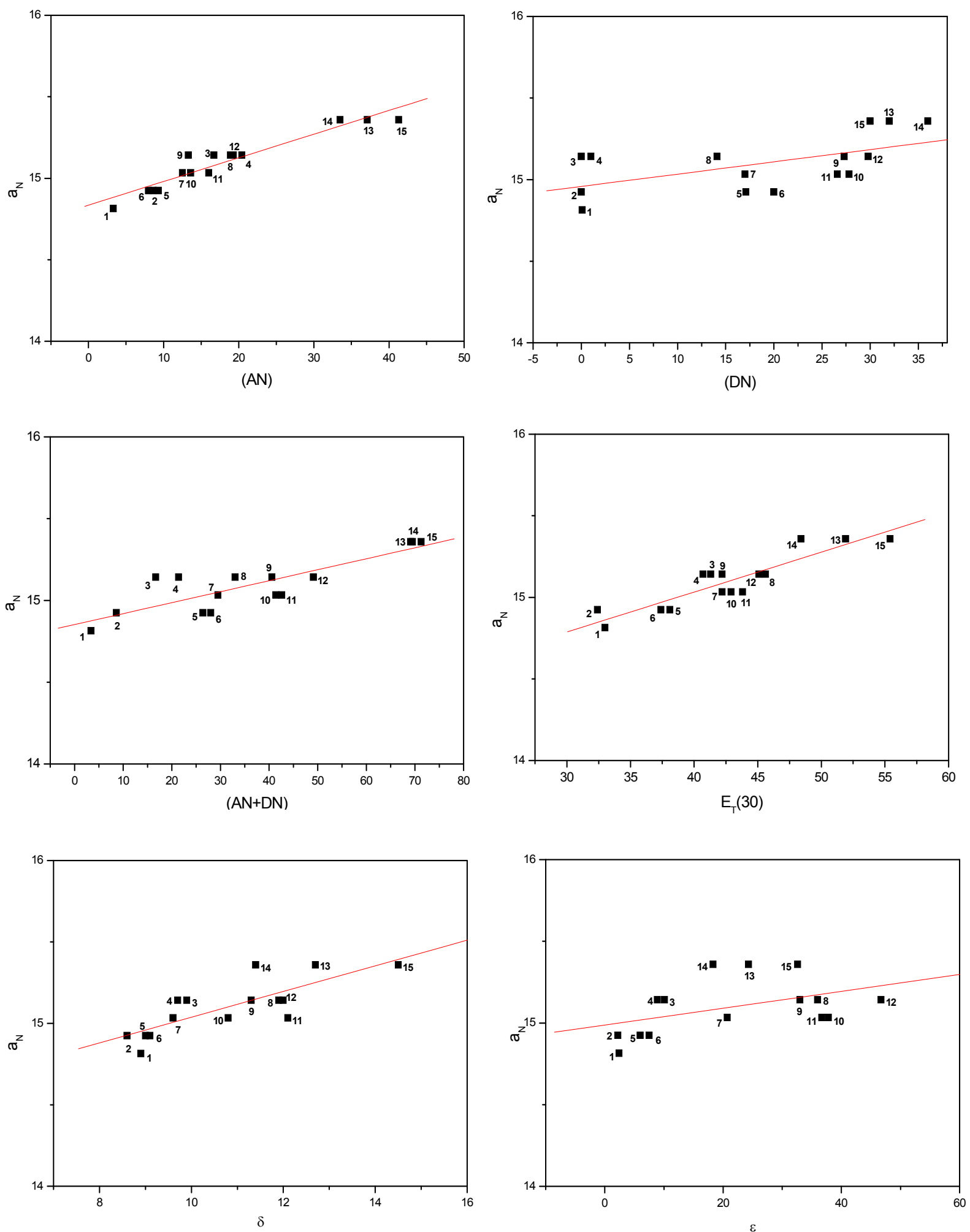
Figure 5. Values of $\mathrm{a}_{\mathrm{N}}$ of nitroxide (C) as a function of solvent $A N, D N,(A N+D N)$, $\mathrm{E}_{\mathrm{T}} 30, \delta$ and $\varepsilon$.
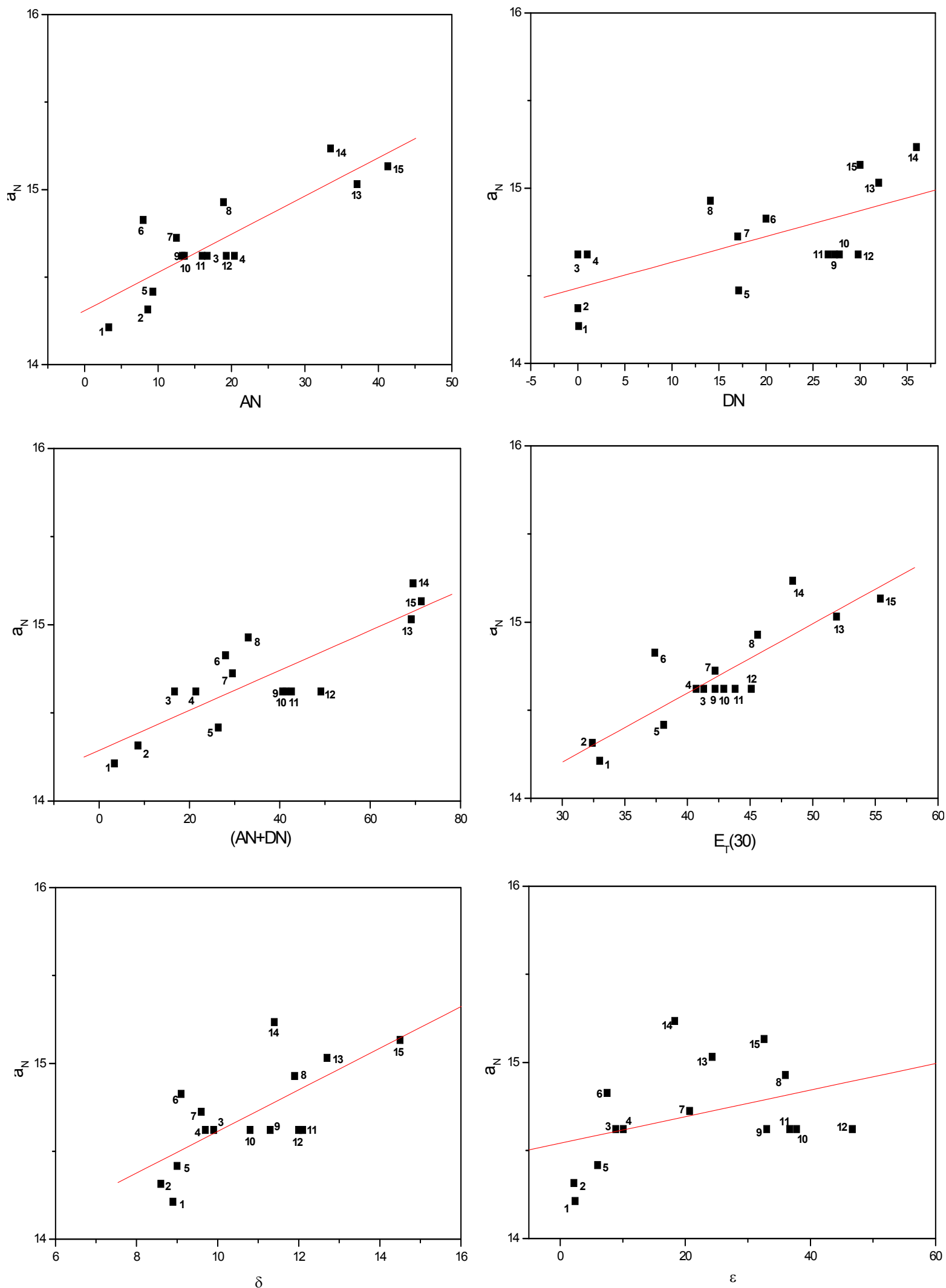
Table 2. Correlations between solvent parameters and $\mathrm{a}_{\mathrm{N}}$ values.

\begin{tabular}{lcccc}
\hline \multirow{2}{*}{ Parameter } & \multicolumn{4}{c}{ Linear regression coefficient (r) } \\
\cline { 2 - 5 } & $\mathbf{A}$ & $\mathbf{B}$ & $\mathbf{C}$ & $(\bar{X})^{\mathbf{a}}$ \\
\hline $\mathrm{AN}$ & 0.94 & 0.95 & 0.84 & 0.91 \\
$\mathrm{DN}$ & 0.66 & 0.58 & 0.66 & 0.63 \\
$(\mathrm{AN}+\mathrm{DN})$ & 0.89 & 0.85 & 0.84 & 0.86 \\
$\mathrm{E}_{\mathrm{T}}(30)$ & 0.95 & 0.91 & 0.86 & 0,91 \\
$\delta$ & 0.86 & 0.79 & 0.70 & 0.78 \\
$\varepsilon$ & 0.56 & 0.45 & 0.39 & 0.47 \\
\hline
\end{tabular}

A: 2,2,6,6-tetramethyl-4-piperidone-1-oxide; B: 5-4-hydantoin-2,2,6,6tetramethyl-4-piperidone-1-oxide; C: 3-carbamoyl-2,2,5,5-tetramethyl-3pyrrolin-1-yloxy; a: Average of linear regression coefficient values.

The relationship between ESR spectral $\mathrm{a}_{\mathrm{N}}$ parameter and the $(\mathrm{AN}+\mathrm{DN})$ or any other polarity or some other physicochemical terms might be also alternatively investigated based on some empirical molecular computational methods $[19,31]$. In this case, it must be first considered the existence of the two canonical structures of the nitroxyl group, shown in Scheme 1:

Scheme 1. Canonical structures of the nitroxide-free radical.

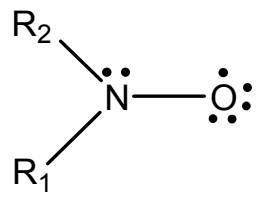

( I )

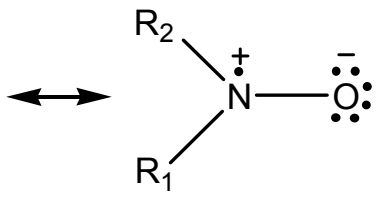

( II )

The difference between these two forms is based upon the localization of the unpaired electron. The structure (II) localizes this electron on the $\mathrm{N}$ atom (for instance, in the case of nitroxide-bearing probe), and is responsible for the ESR three-line ${ }^{14} \mathrm{~N}$ hyperfine splitting. This occurs with more polar/hydrogen donor-type solvents that tend to attract the electronic pair to the atom of oxygen, increasing the $\mathrm{a}_{\mathrm{N}}$ values. Opposite process occurs when in less polar solvents (structure I).

Besides these specific features of the N-O moiety, some aspects of the two $\pi$-molecular orbitals, composed from combination of the $2 \mathrm{p}_{\mathrm{x}}$ atomic orbitals (AO) of $\mathrm{N}$ and $\mathrm{O}$ atoms must be also taken into account. Among the seven electrons of the canonic structure (I), two are in the $\mathrm{N} 1 \mathrm{~s}$ orbital, three associated with the hybridized $\sigma$ molecular orbital of the R1-N, R2-N and N-O bonds. The remaining two electrons are in the $2 \mathrm{p}_{\mathrm{z}} \pi$ orbital. Otherwise, the eight electrons of oxygen atom are distributed as follows: two in the $1 \mathrm{~s} A O$, one in the $2 p_{z} \pi$ orbital, a lone pair in the $2 \mathrm{~s} A O$, one in the $2 p_{y} A O$ and finally, one in the $2 p_{\mathrm{x}} \sigma \mathrm{MO}$ of the $\mathrm{N}-\mathrm{O}$ bond. Thus, for the two-center $\pi$-system, $\mathrm{N}$ and $\mathrm{O}$ atoms contribute with two and one electrons, respectively [31].

Regardless of the molecular orbital method to be applied, these N-O orbital details must be primary considered in combination with some experimental data collected in each type of approach tested. Nevertheless, besides the mentioned works (references [19] and [31]), there are others to be accessed 
for further examining the relationship between the $\mathrm{a}_{\mathrm{N}}$ and solvent polarity terms through the molecular orbital calculation theories [34-36].

In addition, one must remember that the relationship between EPR $\mathrm{a}_{\mathrm{N}}$ parameter and the polarity of the medium examined herein is valid. The early proposed definition of polarity as simply the solvent's overall solvation capability (or solvation power) [19, 37] was officially accepted by the IUPAC committee [38]. In other words, different types of molecular association involving the spin probe and solvent molecules such as hydrogen bonding, van der Waals interaction or any type of electron redistribution in the vicinity of the $\mathrm{N}-\mathrm{O}$ moiety are all, included in the polarity definition.

In summary, results of the present study confirm that the recently proposed (AN+DN) constant seems to fulfill the requisites to be considered an alternative polarity scale. This assertion has been verified in solvent effect studies involving solvation of dozens of polymers and peptide-polymers with different polarity characteristics in nearly 30 single and mixed solvent systems $[3,4]$.

It is of note that the dimensionless $(\mathrm{AN}+\mathrm{DN})$ scale, which ranges from zero (toluene) to almost 130 (trifluoromethanesulfonic acid) [4], has other unique advantage in terms of elucidating the solute solvation effect of solvents. The experiments detailed in a number of studies depict several examples of self-neutralizing effects occurring, for instance, when strong electrophilic trifluoroethanol, hexafluoroisopropanol or water are mixed with strong nucleophilic solvents such as dimethylsulfoxide $[3,4,13,14]$. In such cases, one component trends to interact with its amphoteric counterpart and does not solvate the aggregated solute molecules, inducing their dissociation. This process also occurs in single solvents such as acetonitrile, acetone or isopropanol, which have quite similar electrophilicity and nucleophilicity characteristics (similar $\mathrm{AN}$ and $\mathrm{DN}$ values), inhibiting their capacity to disaggregate, for instance, peptide chains attached to a polymeric matrix or even free in solution. None of the single-term polarity scales, such as $\mathrm{AN}, \mathrm{E}_{\mathrm{T}}(30), \delta$ or $\varepsilon$, can explain these types of important solute-solvent interactions.

\section{Experimental Section}

\subsection{Materials}

The 3-carbamoyl-2,2,5,5-tetramemtyl-3-pyrrolin-1-yloxy used for the synthesis of the POAC spin label was acquired from Aldrich Co. The 2,2,6,6-tetramethyl-4-piperidone-1-oxide and 5-4-hydantoin2,2,6,6-tetramethyl-4-piperidone-1-oxide, both intermediates of the synthesis of the TOAC probe, were obtained as previously described [21, 22]. The solvents were all of analytical grade, were all acquired from different sources and all met American Chemical Society standards.

\subsection{Methods}

The EPR spectra were obtained at $9.5 \mathrm{GHz}$ with a Varian E-4 spectrometer at room temperature $\left(22 \pm 2{ }^{\circ} \mathrm{C}\right)$, using flat quartz cells for liquid solutions (James Scalon, Costa Mesa, CA, USA). The magnetic field was modulated with amplitudes smaller than one-fifth of the linewidths, and the microwave power was set to $5 \mathrm{~mW}$ in order to avoid saturation effects. The spin probe solution was 5 $\times 10^{-5} \mathrm{M}$. Estimated uncertainties are $\pm 0.03 \mathrm{G}$ for $\mathrm{a}_{\mathrm{N}}$ values. 


\section{Acknowledgements}

This study received financial support in the form of grants from the Brazilian scientific agencies Fundação de Amparo à Pesquisa do Estado de São Paulo (FAPESP, Foundation for the Support of Research in the State of São Paulo), Conselho Nacional de Desenvolvimento Científico e Tecnológico (CNPq, National Council for Scientific and Technological Development) and Coordenação de Aperfeiçoamento de Pessoal de Nivel Superior (CAPES, Coordination of the Advancement of Higher Education). L.M. is a postdoctoral fellow of CNPq; SS and CRN are recipients of research fellowships from CNPq.

\section{References}

1. Reichardt, C. Solvatochromic Dyes as Solvent Polarity Indicators. Chem. Rev. 1994, 94, 2319-2358.

2. Katritzky, A.R.; Fara, D.C.; Yang, H.F.; Tamm, K.; Tamm, K.; Karelson, M. Quantitative Measures of Solvent Polarity. Chem. Rev. 2004, 104, 175-198.

3. Cilli, E.M.; Oliveira, E.; Marchetto, R.; Nakaie, C.R. Correlation between Solvation of PeptideResins and Solvent Properties. J. Org. Chem. 1996, 61, 8992-9000.

4. Malavolta, L.; Oliveira, E.; Cilli, E.M.; Nakaie, C.R. Solvation of Polymers as Model for Solvent Effect Investigation: Proposition of a Novel Polarity Scale. Tetrahedron 2002, 58, 4383-4394.

5. Gutmann, V. The Donor-acceptor Approach to Molecular Interactions; Plenum: New York, USA, 1978.

6. Oliveira, E.; Cilli, E.M.; Miranda, A.; Jubilut, G.N.; Albericio, A.; Andreu, A.; Paiva, A.C.M.; Schreier, S.; Nakaie, C.R. Monitoring the Chemical Assembly of a Transmembrane Bradykinin Receptor Fragment: Correlation between Resin Solvation, Peptide Chain Mobility and Rate of Coupling. Eur. J. Org. Chem. 2002, 21, 3686-3694.

7. Barany, G.; Merrifield, R. B. The Peptides: Analysis, Synthesis and Biology. Gross; E., Meienhofer J., Ed.; Academic Press: New York, USA, 1980; pp. 1-284.

8. Kates, S.A.; Albericio, F. Solid Phase Synthesis: A Practical Guide; M. Dekker, Ed.; New York, USA, 2000; pp. 275-330.

9. Fields, G.B.; Noble, R.L. Solid-Phase Peptide-Synthesis Utilizing 9-Fluorenylmethoxycarbonyl Amino-Acids. Int. J. Pept. Prot. Res. 1990, 35, 161-214.

10. Cilli, E.M.; Marchetto, R.; Schreier, S.; Nakaie, C.R. Correlation between the Mobility of Spin Labeled Peptide Chains and Resin Solvation: An Approach to Optimize the Synthesis of Aggregating Sequences. J. Org. Chem. 1999, 64, 9118-9123.

11. Marchetto, R.; Cilli, E.M.; Jubilut, G.N.; Schreier, S.; Nakaie, C.R. Determination of Site-Site Distance and Site Concentration within Polymer Beads: A Combined Swelling-Electron Paramagnetic Resonance Study. J. Org. Chem. 2005, 70, 4561-4568.

12. Nakaie, C.R.; Malavolta, L.; Schreier, S.; Trovatti, E.; Marchetto, R. Direct Electron Paramagnetic Resonance Monitoring of the Peptide Synthesis Coupling Reaction in Polymeric Support. Polymer 2006, 47, 4531-4536. 
13. Malavolta, L.; Nakaie, C.R. Peptide Dissociation in Solution or Bound to a Polymer: Comparative Solvent Effect. Tetrahedron 2004, 60, 9417-9424.

14. Malavolta, L.; Pinto, M.R.S.; Cuvero, J.H.; Nakaie, C.R. Interpretation of the Dissolution of Insoluble Peptide Sequences Base on the Acid-Base Properties of Solvent. Protein Sci. 2006, 15, 1476-1488.

15. Lynn, D.G.; Meredith, S.C. Model Peptides and the Physicochemical Approach to $\beta$-Amyloids. $J$. Struct. Biol. 2000, 130, 153-173.

16. De-Felice, F.G.; Vieira, M.N.N.; Saraiva, L.M.; Figueroa-Villar, J.D.; Garcia-Abreu, J.; Liu, R.; Chang, L.; Klein, W.L.; Ferreira, S.T. Targeting the Neurotoxic Species in Alzheimer's Disease: Inhibitors of A $\beta$ Oligomerization. Faseb J. 2004, 18, 1366-1372.

17. Brière, R.; Lemaire, H.; Rassat, A. Nitroxydes XV: Synthese et Etude de Radicaux Libres Stables Pipéridiniques et Pyrrolidinique. Bull. Soc. Chim. Fr. 1965, 3273-3283.

18. Marsh, D. Polarity Contributions to Hyperfine Splittings of Hydrogen-Bonded Nitroxides - The Microenvironment of Spin Labels. J. Magn. Reson. 2002, 157, 114-118.

19. Plato, M.; Steinhoff, H.J.; Wegener, C.; Torring, J.T.; Savitsky, A.; Möbius, K. Molecular Orbital Study of Polarity and Hydrogen Bonding Effects on the $\mathrm{G}$ and Hyperfine Tensors of Site Directed NO Spin Labeled Bacteriorhodopsin. Mol. Phys. 2002, 100, 3711-3721.

20. Marsh, D.; Toniolo, C. Polarity Dependence of EPR Parameters for TOAC and MTSSL Spin Labels: Correlation with DOXYL Spin Labels for Membrane Studies. J. Magn. Res. 2008, 190, 211-221.

21. Rassat, A.; Rey, P. Nitroxydes. 23. Préparation Dàminoacides Radicalaires et de Leurs Sels Complexes. Bull. Soc. Chim. Fr. 1967, 815-817.

22. Rozantsev, E.G. Free Nitroxyl Radicals; Plenum Press: New York, USA, 1970.

23. Nakaie, C.R.; Goissis, G.; Schreier, S.; Paiva, A.C.M. pH Dependence of ESR Spectra of Nitroxide Containing Ionizable Groups. Braz. J. Med. Biol. Res. 1981, 14, 173-180.

24. Marchetto, R.; Schreier, S.; Nakaie, C.R. A Novel Spin-Labeled Amino Acid Derivative for Use in Peptide Synthesis: (9-Fluorenylmethyloxycarbonyl) 2,2,6,6-Tetramethylpiperidine-N-Oxyl-4Amino-4-Carboxylic Acid. J. Am. Chem. Soc. 1993, 115, 11042-11043.

25. Tominaga, M.; Barbosa, S.R.; Poletti, E.F.; Zukerman-Schpector, J.; Marchetto, R.; Schreier, S.; Paiva, A.C.M.; Nakaie, C.R. Fmoc-POAC: [(9-Fluorenylmethyloxycarbonyl)-2,2,5,5Tetramethylpyrrolidine-N-Oxyl-3-Amino-4-Carboxylic acid]: A Novel Protected Spin Labeled Beta-amino Acid for Peptide and Protein Chemistry. Chem. Pharm. Bull. 2001, 49, 1027-1029.

26. Dimroth, K.; Bohlman, F.; Reichardt, C.; Siepmann, T. Uber Pyridinium-N-Phenol-Betaine Und Ihre Verwendung Zur Charakterisierung Der Polaritat Von Losungsmitteln. Liebigs. Ann. Chem. 1963, 661, 1-37.

27. Barton, A. F. M. Solubility Parameters. Chem. Rev. 1975, 75, 731-753.

28. Parker, A.J. Protic-Dipolar Aprotic Solvent Effects on Rates of Bimolecular Reactions. Chem. Rev. 1969, 69, 1-32.

29. Chastrette, M.; Carretto, J. Statistical Study of Solvent Effects-II Analysis of Some Empirical Parameters of Solvent Polarity. Tetrahedron, 1982, 38, 1615-1618.

30. Berliner, J.L.; Reuben, J. Spin Labeling Theory and Applications; Plenum Press: New York, 1989. 
31. Griffith, O.H.; Dehlinger, P.J.; Van, S.P. Shape or the Hydrophobic Barrier of Phospholipids Bilayers (Evidence for Water Penetration in Biological Membranes). J. Memb. Biol. 1974, 15, 159-192.

32. Subczynski, W.K.; Wisniewska, A.; Yin, J.J.; Hyde, J.S.; Kusumi, A. Hydrophobic Barriers of Lipid Bilayer Membranes Formed by Reduction of Water Penetration by Alkyl Chain Unsaturation and Cholesterol. Biochemistry 1994, 33, 7670-7681.

33. Marsh, D. Reaction Fields and Solvent Dependence of the EPR Parameters of Nitroxides: the Microenvironment of Spin Labels. J. Mag. Res. 2008, 190, 60-67.

34. Stewart, J.J.J. Optimization of Parameters for Semiempirical Methods. II. Applications. J. Comput. Chem. 1989, 10, 221-264.

35. Un, S.; Atta, M.; Fontecave, M.; Rutherford, A.W. G-values as a Probe for the Local Protein Environment: High-field EPR of Tyrosyl Radicals in Ribonucleotide Reductase and Photosystem II. J. Am. Chem. Soc. 1995, 117, 10713-10719.

36. Engström, M.; Owenius, R.; Vahtras, O. Ab Initial G-tensor Calculations of Hydrogen Bond Effects on a Nitroxide Spin Label. Chem. Phys. Lett. 2001, 338, 407-413.

37. Reichardt, C. Empirical Parameters of the Polarity of Solvents. Angew. Chem. 1965, 77, 30-40.

38. Müller, P. Glossary of Terms Used in Physical Organic Chemistry (IUPAC Recommendations 1994). Pure Appl. Chem. 1994, 66, 1077-1184.

(C) 2008 by the authors; licensee Molecular Diversity Preservation International, Basel, Switzerland. This article is an open-access article distributed under the terms and conditions of the Creative Commons Attribution license (http://creativecommons.org/licenses/by/3.0/). 